\title{
Simulation Emergency Fire Evacuation Model for Nuclear Power Plant
}

\author{
Amany F. Abd El-Aal1, Adel Zaghloul², Magy M. Kandil ${ }^{3 *}$ \\ ${ }^{1}$ National Radiation Monitoring Network, Egyptian Nuclear \& Radiological Regulatory Authority, Cairo, Egypt \\ ${ }^{2}$ Electronic and Communication Department, Faculty of Engineering, Zagazig University (Currently at Delta University), Gamasa, Egypt \\ ${ }^{3}$ Nuclear Law and Licenses Department, Egyptian Nuclear\& Radiological Regulatory Authority, Cairo, Egypt \\ Email: *magy_kandil@yahoo.com
}

How to cite this paper: Abd El-Aal, A.F., Zaghloul, A. and Kandil, M.M. (2021) Simulation Emergency Fire Evacuation Model for Nuclear Power Plant. Journal of Power and Energy Engineering, 9, 30-52. https://doi.org/10.4236/jpee.2021.94003

Received: February 25, 2021

Accepted: April 11, 2021

Published: April 14, 2021

Copyright $\odot 2021$ by author(s) and Scientific Research Publishing Inc. This work is licensed under the Creative Commons Attribution International License (CC BY 4.0).

http://creativecommons.org/licenses/by/4.0/ (c) (i) Open Access

\begin{abstract}
Simulation of egress is vital for minimizing losses during fire disasters, however accurate simulations are scarce and real-life data is hard to come by. In this paper, a Proposed Wireless Fire Evacuation Model (PWFEM) is proposed to simulate fire evacuation process in a short time to minimize evacuee's exposure to the harmful radiation and fire hazards. The PWFEM simulation realistic by supposing fire scenario at cabined contains electrical cables inside a standard Main Control Room (MCR) in a Nuclear Power Plant (NPP) building. In addition, a new Hybrid Safest Shortest Exit (HSSE) is developed which consists of three stages: safest route based on rules-based technique, evacuees location based on the DV-hop technique [1] and shortest route that depends on Dijkstra technique. The PWFEM Simulations are appreciated to yield a realistic fire scenario by using a telecommunications TCP/IP network in form of server and client sides that help in transfer data inside internal networks in the NPP building. On the server-side, suppose that Consolidated Model of Fire Growth and Smoke Transport (CFAST) fire modeling is applied to simulate the fire scenario in MCR through CFAST model to generate fire products as output data in excel sheets and sends them to the client-side. The client-side then runs HSSE to produce the tree map for safest and shortest routes to help the evacuee for safe exit from his/her location. HSSE can be implemented on evacuee's watches. From the results, it is concluded that PWFEM can simulate the fire scenario inside MCR, furthermore it is validated that HSEE can be used as an efficient emergency fire evacuation technique that can produce safest and shortest exit route for evacuee in any location inside NPP in very small time. In addition, PWFEM can be used for simulating fire evacuation inside any high-risk buildings and can appreciate yielding any realistic fire scenario with many types of fire sources in different places inside buildings.
\end{abstract}




\section{Keywords}

Fire Safety, Fire Evacuation Model, NPP Evacuation, Localization Technique, CFAST Model, DV-Hop Technique, Dijkstra Algorithm

\section{Introduction}

Nuclear Power Plants (NPPs) are a facility for electrical energy generation developed for operating on a continuous regime. Fire is a noteworthy hazard for NPP's safety. Fire events may occur in any part of any NPP. Browns' Ferry fire was the worst fire event in NPPs [2]. Fire safety in NPPs intended to ensure the highest level of safety that can reasonably be achieved by the protection for operators, workers, and other public, environment, and investment [3]. It started in phase of NPP design and for all the plant life. In NPPs, fire emergency evacuation plans are requirement from safety authorities and regularities for licenses and also, take into account the fire risk assessment, fire risk management and successful evacuation [4]. The NPPs' buildings should follow the fire protection rules that have been constrained by the safety authorities for safety. In NPP the fire protection concerning about the safety of buildings and people thus Emergency fire evacuation in NPPs is very important since, it concerns of the safety of operators, workers and public outside. In this research, the main goal is to identify the suitable shortest and safest route inside building as NPP for accomplishing fire emergency evacuation in less time. Evacuation management for nuclear power fire accident involves a number of processes and factors that are evacuated in a smallest time thus determining the safe and shortest routes are considered as the most important evacuation's criteria [5].

Most of the previous works in evacuation models are developing to obtain the optimal route of buildings or public places for minimizing the total evacuation time only. Evacuation models are becoming a part of performance-based analyses to assess the level of life safety. Evacuation computer models achieve a more realistic evacuation calculation to assess evacuee's life safety and reduce the predicted evacuation time. Emergency fire evacuation models can be categorized [6] as simulation models, dynamic programming models, and approximation and heuristic methods. Computational model [7] uses prediction data on smoke propagation inside a structure obtained from Fire Dynamics Simulator to identify evacuation fastest escape route by $\mathrm{A}^{*}$ algorithm [8]. Evacuation model simulates the proper shortest and safest route [9] and dynamic road network model by implementing the Dijkstra Algorithm [10].

In this research, a new hybrid Safest Shortest Exit (HSSE) algorithm for protecting evacuees, as operator, worker and other public which consists of three stages. In the first stage, the safest route is determined based in rules-based technique, called IF-Else algorithm [11] [12]. The second stage locates the evacuees' location based on the DV-hop technique since it is the most accurate location 
calculations than other techniques, which depends on the average hop count [1] [13]. The third stage determines the shortest route depend on Dijkstra technique which is a graph search algorithm that solves the single-source shortest path problem in the smallest time [14]. HSSE algorithm can be implemented in evacuee's watch to estimate the safest and shortest exit route from his/her location. HSEE is simulated at an MCR in an NPP fire using the Proposed Wireless Fire Evacuation Model (PWFEM) to imitate emergency fire evacuation cases in NPP.

\section{The Proposed Wireless Fire Evacuation Model (PWFEM)}

The Proposed Wireless Fire Evacuation Model (PWFEM) is simulated using telecommunications TCP/IP network as shown in Figure 1 consists of two parts server side and client side. In TCP/IP of PWFEM assume that, the server side collects the fire products which are assumed producing inside the wireless fire sensors, and sends to the client side. PWFEM is performed to imitate and simulate an emergency fire evacuation model. A fire scenario inside standard Main Control Room (MCR) is ignited and simulated as the server side using CFAST that generates fire hazard products as output data in Excel sheets for HCL, CO, $\mathrm{CO}_{2}$ that are sent to the client side. Moreover, evacuee's watch, is simulated as client side, which after start fire, reviver the fire products data then runs the suggested hybrid Safest Shortest Exit (HSSE) algorithm to identify the Safest Shortest Exit route from the NPP building for evacuees (operator, worker and visitors).

\subsection{The First Part of the PWFEM (Server-Side)}

The First Part of the PWFE, a CFAST as a fire simulation zone model is applied to simulate a fire scenario in MCR which is considered in the server-side of the TCP/IP network. The fire modeling, CFAST calculations separate the MCR into two zones, commonly referred as the upper and lower layers. These layers are based on the physics and dynamics of fire ignition inside an enclosure, which includes the fire plume, combustion products, and air entrainment [15] [16]. The temperature and gaseous products from fire events have the main effect on the emergency evacuation [17].

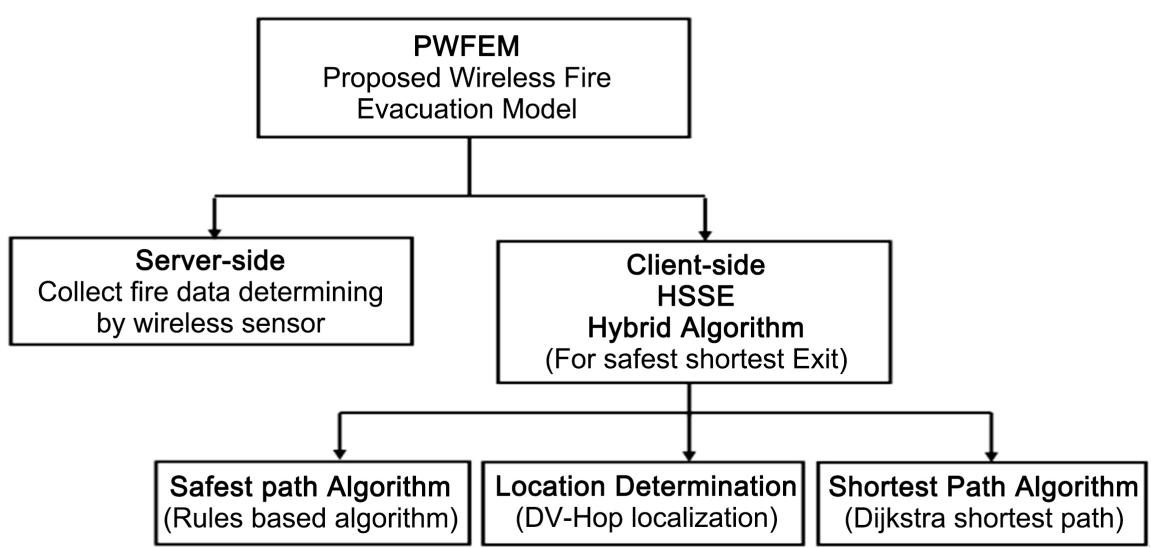

Figure 1. The proposed wireless fire evacuation model (PWFEM) block diagram. 


\section{CFAST Fire Simulation}

The CFAST simulation starts a fire scenario by considering the fire ignition started in cables inside the control cabinet in the standard Main Control Room (MCR) in NPP, which contains control cables [18]. The fire ignites due to an electrical malfunction in bundles of qualified XPE/neoprene cables inside an isolated control cabinet, designated as the Fire Origin Cabinet. The cabinet's positions in the standard MCR are shown in Figure 2. These cabinets' width, length, and height are $0.5 \mathrm{~m}, 1.0 \mathrm{~m}$ and $1.2 \mathrm{~m}$ respectively while the absolute width, length, and height are $1.5 \mathrm{~m}, 3.0 \mathrm{~m}$ and $2.1 \mathrm{~m}$ respectively. The fire grows according to the t-squared curve to a maximum value of $702 \mathrm{~kW}$ in $12 \mathrm{~min}$ and remains steady for eight additional minutes for a low-voltage cabinet fire involving more than one bundle of qualified cable. After $20 \mathrm{~min}$, the fire's Heat Release Rate (HRR) decays linearly to zero in $19 \mathrm{~min}$. A peak fire intensity of 702 $\mathrm{kW}$ represents the $98 \%$ percentage of distribution probability for the HRR in the cabinets of this general description. The door of the standard MCR is open and ventilation conditions are the place condition at the fire start. The ambient parameters of the simulation are temperature $\left(20^{\circ} \mathrm{C}\right)$ and presser $(101,300 \mathrm{~Pa})$, fire

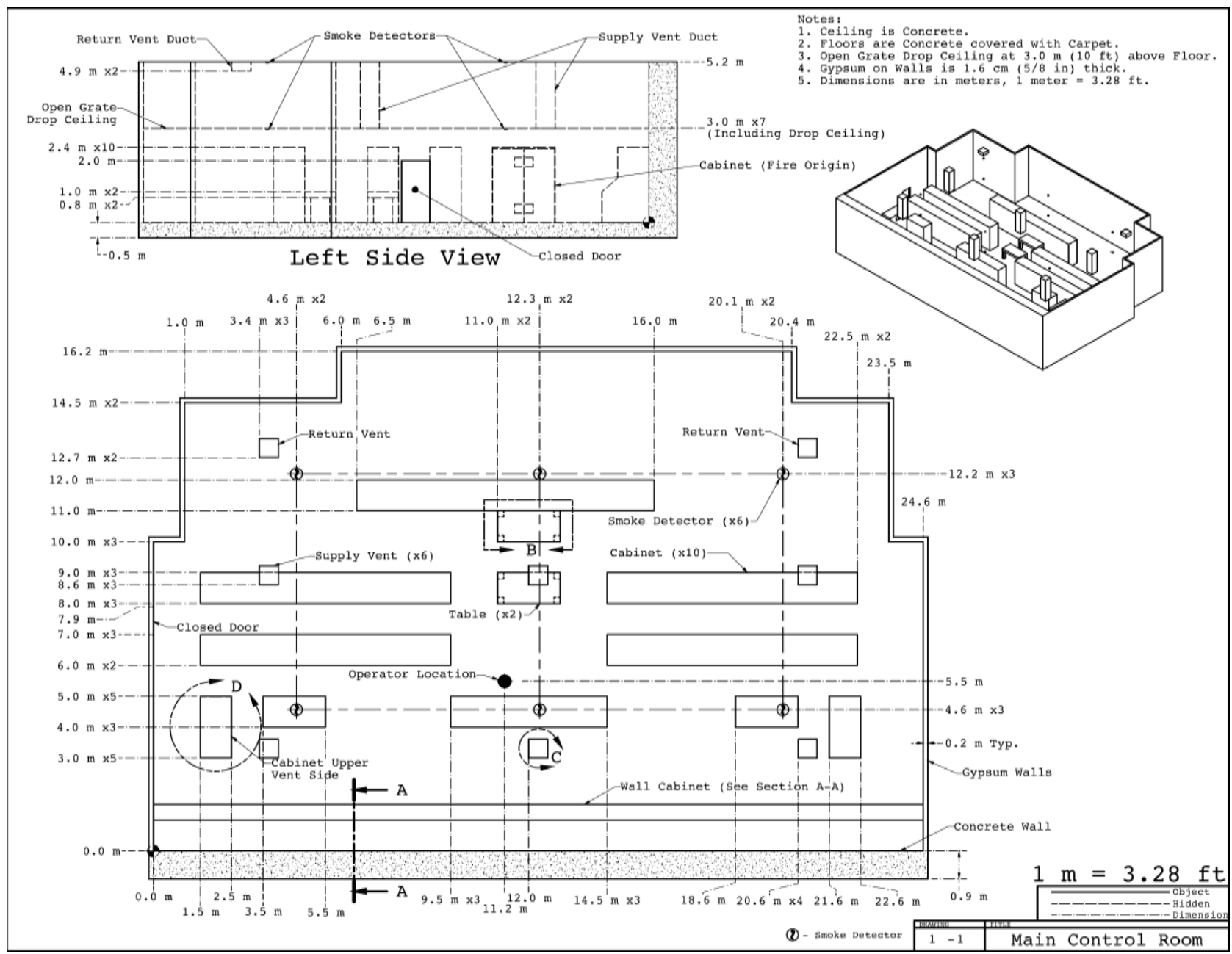

Figure 2. The geometry of the standard Main Control Room (MCR) [22]. 
ignition parameter fire grows according to $\mathrm{t}$-squared curve with the maximum value of $(702 \mathrm{~kW})$ and source of fire with a heat of combustion $(10,300 \mathrm{~kJ} / \mathrm{kg})$ [19] during simulation time 900s. The simulation results generate the fire parameter such as temperature, pressure, water vapor to estimate the results of the fire scenario from different fire gasses emissions such as smoke $\mathrm{CO}_{2}, \mathrm{CO}, \mathrm{HCL}$ and determines the percentage of $\mathrm{O}_{2}$ and toxic species in both of two layers [20] [21].

The HRR curve is shown in Figure 3. Based on a physical assessment of the cabinet, it is determined that the exterior panels of the burning cabinets do not open before or during the fire [23]. The smoke, heat, and flames are exhausted from an air vent in the side of the cabinet. The top of the air vent is $0.3 \mathrm{~m}$ below the top of the cabinet. The air vent is $0.6 \mathrm{~m}$ wide and $0.2 \mathrm{~m}$ high. The cabinet is $2.4 \mathrm{~m}$ tall. The jacket and insulation material of the cable is taken as an equal-parts mixture of polyethylene $\left(\mathrm{C}_{2} \mathrm{H}_{4}\right)$ and neoprene $\left(\mathrm{C}_{4} \mathrm{H}_{5} \mathrm{Cl}\right)$, with the effective chemical formula $\mathrm{C}_{3} \mathrm{H}_{4.5} \mathrm{C}_{10.5}$. The heat of combustion and product yields for XPE/neoprene cable considered with $\mathrm{t}$-squared fire grows as a formula of time squared as flowing:

$$
\dot{Q}(t)=\dot{Q}_{\text {peak }}(t)\left(\frac{t}{t_{\text {peak }}}\right)^{2}
$$

where: $\dot{Q}(t)$ is the $Q$ point of fire with time, $\dot{Q}_{\text {peak }}(t)$ is the $Q$ point at fire peak, $\mathrm{t}$ is the simulation time, and $t_{\text {peak }}$ is the time at fire peak.

The simulation fire scenario in PWFEM, the fire grows to arrive at other three besides cabinets. A fire is described as a source of heat placed at a specific point, within cabinets inside standard MCR that generates combustion products according to specified combustion chemistry. CFAST fire ignition in the standard MCR is represented in Figure 4. Consistent with typical practice for the use of zone fire models for electrical cabinet's fires, the fires are positioned at the top of the air vent, $0.3 \mathrm{~m}$ below the top of the cabinets, at the center of the cabinet. The air vent dimensions are $0.6 \mathrm{~m}$ wide and $0.2 \mathrm{~m}$ height. The effective diameter of the fire is approximately $0.4 \mathrm{~m}$. The fire simulated parameters of the heat of combustion and product yields for XPE/neoprene cable used in CFAST as fire source shown in Table 1.

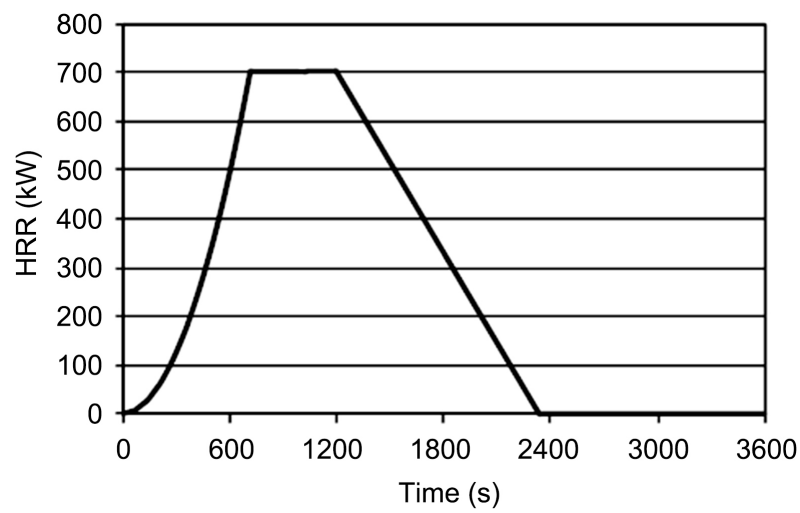

Figure 3. Fire heat release rate in the standard MCR. 


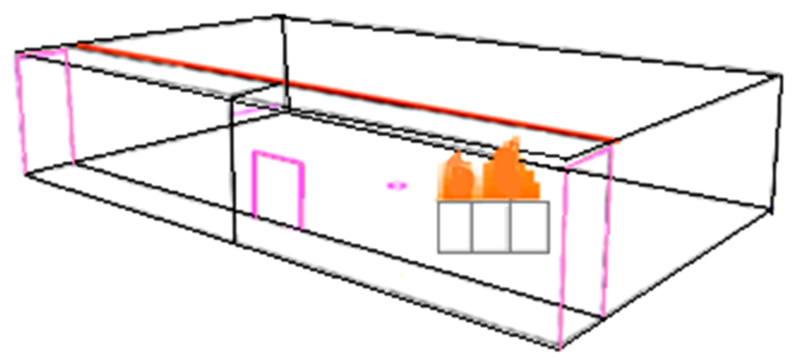

Time 3600

Figure 4. Fire ignition in MCR.

Table 1. The combustion heat and product yields for XPE/neoprene cable [22].

\begin{tabular}{cc}
\hline Parameter & Value \\
\hline $\begin{array}{c}\text { Effective Fuel Formula (Combination of } \\
\text { polyethylene and neoprene) } \\
\text { Peak HRR }\end{array}$ & $\mathrm{C}_{3} \mathrm{H}_{4.5} \mathrm{C}_{10.5}$ \\
Time to reach peak HRR & $702 \mathrm{~kW}$ \\
Heat of Combustion & $720 \mathrm{~s}$ \\
$\mathrm{CO}_{2}$ Yield & $10,300 \mathrm{~kJ} / \mathrm{kg}$ \\
Soot Yield & $0.63 \mathrm{~kg} / \mathrm{kg}$ \\
CO Yield & $0.175 \mathrm{~kg} / \mathrm{kg}$ \\
Radiative Fraction & $0.082 \mathrm{~kg} / \mathrm{kg}$ \\
Mass Extinction Coefficient & 0.53 \\
\hline
\end{tabular}

\subsection{The Second Part of PWFEM (Client-Side)}

In this part, the Hybrid Safest shortest Evacuation algorithm (HSSE) is simulated to determine the safest shortest suitable exit route for each evacuee that can be implemented in evacuee's watch (client-side). Evacuees received CFAST simulation fire output results data from the server-side. HSSE algorithm is implemented for determining evacuees' location, Shortest and Safest Exit graph route him. HSSE divided into three stages as shown in Figure 5. In the first stage the safest routes are detected using a rule-based technique, in the second stage the evacuee's location determination based on the Wireless Localization Algorithm DV Hop technique and in the third stage shortest route is determined based on the Dijkstra technique as shown in Figure 5.

\subsubsection{The First Stage (Determine the Evacuee's Safest Route)}

In the first stage, the evacuee's safest route in the HSSE algorithm is determined. 
In the first, it involved import matrix data from the server-side, using MCR fire products to avoid more dangerous routes that have high toxic fire radiated, hazard gases and which have high temperatures. After that, the safest routes are generated using a rule-based algorithm [24], to assist in generating the Safest Route. The Rules typically take the form of a \{IF: THEN\} expression. Therefore rule-based methods typically comprise a set of rules that collectively make up the calculation model as shown in Figure 6.

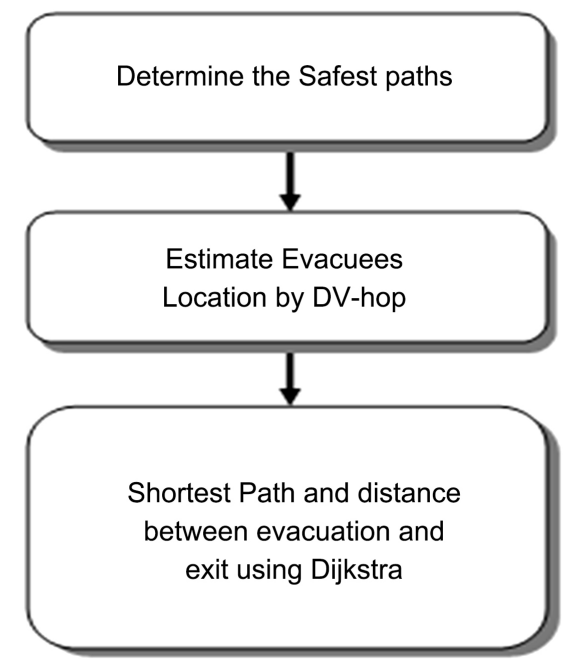

Figure 5. HSSE algorithm block diagram.

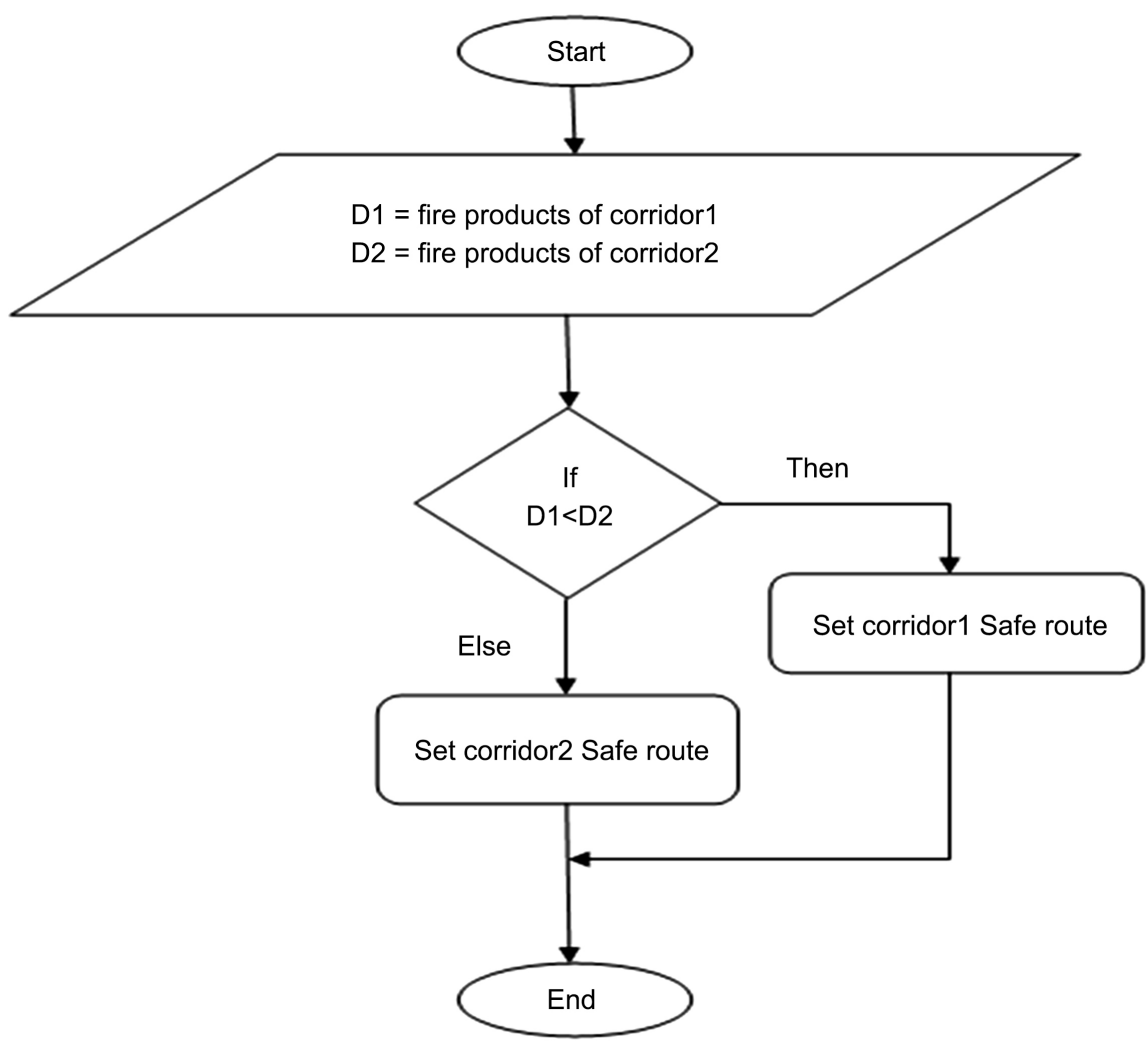

Figure 6. Rule base flow chart. 


\subsubsection{The Second Stage (Estimate Evacuees Location)}

In the suggested HSSE algorithm, the evacuees' location must be determined to estimate the safest and shortest route from evacuee's location from NNP building thus, the second step in the HSSE determining the evacuee's location using localization technique. Moreover, in this stage, the safest route in the HSSE algorithm is involved at Import localization matrix of data. The algorithm plots the matrix data in a Visibility graph. The Visibility graph represents the route as it can be understood by displaying the relationship of nodes and edges. The relationship is connected way based on the weight from the matrix data.

Localization techniques have been generally addressed which is used for location-based services depended on the target detection [25], tracking of the nodes [26], topology control [27], clustering [28] and data tagging [29]. In HSSE wireless localization algorithm based on the DV-hop technique is used to estimate the coordinate of evacuees that can be random distributed in NPP building. Wireless sensor network (WSN) possesses a very broad application prospect in many fields, where the node location technology is one of the key technologies of WSN. Distance Vector Hop (DV-Hop) localization algorithm is a widely used algorithm in this technology, and it uses routing exchange protocol [30] to make unknown nodes obtain beacon node information which will be used for coordinate calculation, therefore there exists certain error for the algorithm itself. Aiming at the disadvantage of large error existing in the traditional wireless sensor network location algorithm based on DV-Hop. In DV-Hop algorithm based on hop thinning and distance correction is applied as shown in Figure 7. $\mathrm{A}, \mathrm{B}$ and $\mathrm{C}$ are three anchor beacons presented by triangles while unknown nodes represent by $n 1$ to $n$.

The simulation of HSSE for determining the Evacuees location in random distributed in NPP building is implemented using localization algorithm based on DV-hop technique through three steps as following:

1) The first step: Determining minimum hop counts of every evacuee's node

The evacuation region is simulated in the NPP building through assumed to be a square area with a fixed size of $100 \times 100 \mathrm{~m}^{2}$, the radio range $(\mathrm{R})$ is set to 50 meters as shown in Figure 8. 50 nodes contain evacuees, are randomly deployed with 5 anchors [31] nodes.

2) The second step: Determining average hop distance

Each anchor estimates average distance per hop (Avg Hop Distance) as flowing:

$$
\text { Avg Hop Distance }=\frac{\sum_{j=1 j \neq i}^{n} \sqrt{\left(x_{i}-x_{j}\right)^{2}+\left(y_{i}-y_{j}\right)^{2}}}{\sum_{j=1 j \neq i}^{n} h_{j}}
$$

where: $n$ is the total number of anchors in the network, $\left(x_{i}, y_{i}\right)$ and $\left(x_{j}, y_{j}\right)$ represent coordinates of anchor $i$ and anchor $j, h_{j}$ is the hop-size between beacon $i$ and beacon $j$. 


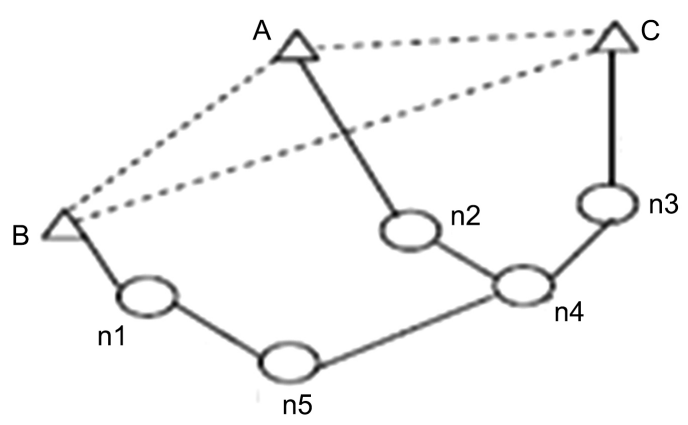

Figure 7. Distance vector hop localization (DV-Hop).

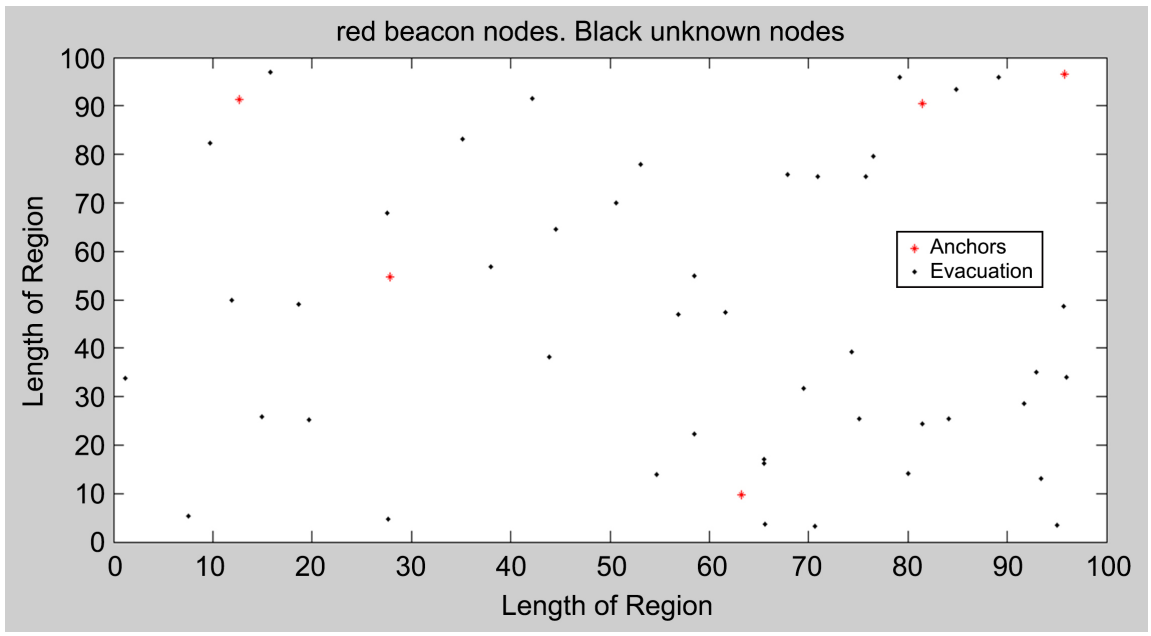

Figure 8. Random arrange of evacuees nodes.

The node who does not know its localization site computes its distance from the anchor as flowing:

$$
d_{i}=\text { Avg Hop Distance } \times h_{i}
$$

where: $d_{i}$ is the distance from node to anchor and $h_{i}$ is the hop-size from node to anchor.

3) The third step: Determining coordinates of unknown evacuee's nodes

Each unknown evacuee node determines its location using a multilateration method [32]. Multilateration method states that $\left(x_{n}, y_{n}\right)$ the coordinates of unknown evacuee's nodes and $\left(x_{i}, y_{i}\right)$ the coordinates for anchor and consent to there are total $\mathrm{m}$ anchors as in (4), the matrix form is (5).

$$
\left.\begin{array}{c}
\left(x_{n}-x_{1}\right)^{2}+\left(y_{n}-y_{1}\right)^{2}=d_{1}^{2} \\
\left(x_{n}-x_{2}\right)^{2}+\left(y_{n}-y_{2}\right)^{2}=d_{2}^{2} \\
\vdots \\
\left(x_{n}-x_{m}\right)^{2}+\left(y_{n}-y_{m}\right)^{2}=d_{m}^{2}
\end{array}\right\}
$$

where: 


$$
\begin{gathered}
A=2 \times\left[\begin{array}{cc}
x_{1}-x_{m} & y_{1}-y_{m} \\
x_{2}-x_{m} & y_{2}-y_{m} \\
\vdots & \vdots \\
x_{m-1}-x_{m} & y_{m-1}-y_{m}
\end{array}\right] \\
X_{n}=\left[\begin{array}{c}
x_{n} \\
y_{n}
\end{array}\right]
\end{gathered}
$$

and

$$
B=\left[\begin{array}{ccc}
x_{1}^{2}-x_{m}^{2} & +y_{1}^{2}-y_{m}^{2} & -d_{1}^{2}-d_{m}^{2} \\
x_{1}^{2}-x_{m}^{2} & +y_{1}^{2}-y_{m}^{2} & -d_{1}^{2}-d_{m}^{2} \\
\vdots & \\
x_{m-1}^{2}-x_{m}^{2} & +y_{m-1}^{2}-y_{m}^{2} & -d_{m-1}^{2}-d_{m}^{2}
\end{array}\right]
$$

The coordinate of unknown evacuees nodes calculated as flowing:

$$
X=\left(A^{\mathrm{T}} A\right)^{-1} A^{\mathrm{T}} B
$$

In this research, the mean square localization error is chosen to evaluate the performance of the proposed algorithm. The error calculated by:

$$
\text { error }=\sum_{n=1}^{N} \frac{\sqrt{\left(X_{n}-X_{n}^{\prime}\right)^{2}-\left(Y_{n}-Y_{n}^{\prime}\right)^{2}}}{N \times \text { range }}
$$

where: $\left(X_{n}, Y_{n}\right)$ are the estimated coordinates of unknown evacuees node $\mathrm{N}$, $\left(X_{n}^{\prime}, Y_{n}^{\prime}\right)$ are the actual coordinates, the range is the communicate radius of the network and $\mathrm{N}$ is the total number of the nodes inside the range.

In HSSE the three steps of DV-Hop Algorithm are applied in the evacuation region of simulation assumed to be a square area with a fixed size of $100 \times 100$ $\mathrm{m}^{2}$ with radio range $(\mathrm{R})$ is set to 50 meters and fifty evacuees, or nodes, are randomly deployed in a two-dimensional space with 5 anchor nodes as shown in Figure $7 \&$ Figure 8. Each anchor node transmits its location information to its neighbor nodes. The neighbor nodes additionally convey to their neighbor nodes, so that small packet broadcasts for all the nodes in the network get this information. The packet contains information of $\mathrm{x}$ and $\mathrm{y}$ coordinates of anchor node and hop count. The initial value of the hop count is 0 . Each node affirms its hop count table including the number of anchors, $\mathrm{x}$ and $\mathrm{y}$ coordinates of anchor node and anchor hop count. Any node checks its table when received the packet and if the value of hop count in its table is less than hop count value received. The node ignores that received value otherwise it increments hop count value by 1 and saves the new value of hop count for anchor node in its table. It broadcast the updated packet with hop count value to its neighbors. After that, each node gets the smallest hop-count from every anchor node and has an updated hop-count table.

\subsubsection{Third Stage (Determine the Evacuee's Shortest Route)}

Determining the evacuee's shortest route is implemented in the client-side as a third stage of the HSSE algorithm that can be propagated in the evacuee's watch 
for determining shortest route for the safest route from him/her location, during evacuating from the NNP building. In Dijkstra's Shortest Route algorithm [33], the goal is finding the shortest routes between nodes that produce in a graph. Dijkstra's finds the shortest route between two nodes as shown in Figure 9. The source node is acting as a single fixed node and finds the shortest routes from the source to all other nodes in the graph producing the shortest route tree depend on a min-priority queue [34]. In HSSE Dijkstra Algorithm has been chosen not only for its efficiency in producing the shortest route for selection of route but also, it can provide an evacuation plan for the evacuee that can be represented as shortest route tree. In HSSE, the Shortest path algorithm characterizes each node of each evacuee by its state. The state of a node consists of two features distance value and status label. The distance value of an evacuee node is a scalar representing an estimate of its distance from the evacuee node. Status label is an attribute specifying whether the distance value of a node is equal to the shortest distance to the evacuee node or not. The status label of a node is Permanent if its distance value is equal to the shortest distance from evacuee node Otherwise, the status label of a node is Temporary The algorithm maintains and step-by-step updates the states of the nodes, at each step one node is designated as current, after that the final safest and shortest route determined in tree visual graph as seen in the results.

\section{Results and Discussion}

\subsection{The First Part (CFAST Simulation) Results}

The temperature and gaseous products from the fire events have the main effect in the emergency evacuation; so that in this part, the products data of the fire scenario modeling that the applied in the standard MCR and two selected corridors during fire assume data collected from wireless sensors output data such as temperatures, the visible smoke and gas species concentrations within each layer. The produced gaseous and the temperatures develop with the simulation time. Fallouts in this work are obtained at $20^{\circ} \mathrm{C}$ during the fire scenario time of $900 \mathrm{~s}$ with mechanical ventilation.

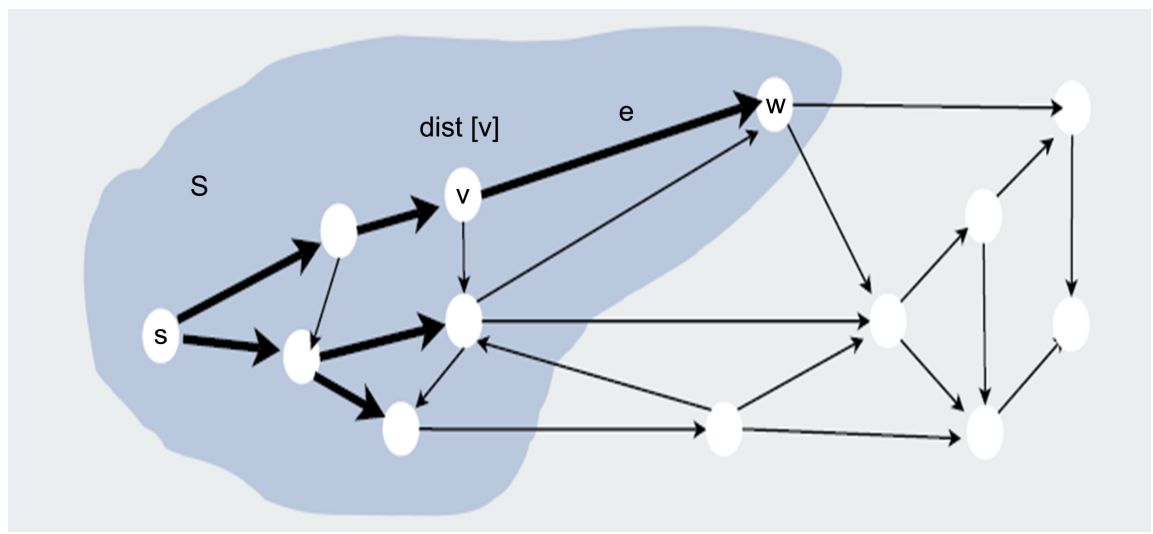

Figure 9. The route nodes obtained using Dijkstra Algorithm. 


\subsubsection{The Fire Temperature}

The fire is affected by the temperature because heat is one of fire Ignition and combustion requirements. Also, fire rate increases as temperature raise and warm fuels ignite faster since less heat energy is needed to raise fuel ignition temperature. The temperature of fire affects the human body due to heat transfer from the high-temperature fire to the human body which is relatively lower temperature [35], so that it is very important to know the temperature and measuring it during the fire.

\section{1) The temperature in the upper layer in standard MCR and corridors}

The upper layer temperature of the standard control room and the corridors during the fire growth and expansion are forward proportional with the time and then saturated. In the beginning, the upper layer temperatures of the standard MCR and the corridors is a slow increase in the interval from $0 \mathrm{sec}$ to 250 sec while a fast increase in the interval from $650 \mathrm{sec}$ to $900 \mathrm{sec}$ as shown in Figure 10. The difference in temperature between the control room and two corridors depends on the flux flow and the ventilation in each compartment.

\section{2) The temperature in the lower layer in standard MCR and corridors}

The lower layer temperature of the standard control room and the corridors during the fire growth and expansion is stable to $20^{\circ} \mathrm{C}$ during the interval from 0 sec to $300 \mathrm{sec}$. it begins in a proportional increase in standard MCR from $20^{\circ} \mathrm{C}$ up to $55^{\circ} \mathrm{C}$ at interval from $300 \mathrm{sec}$ to $900 \mathrm{sec}$. the increase in corridors temperature delayed until $600 \mathrm{sec}$ depending on the heat transfer and ventilation. The lower layer temperatures of the standard MCR and the corridors are shown in Figure 11.

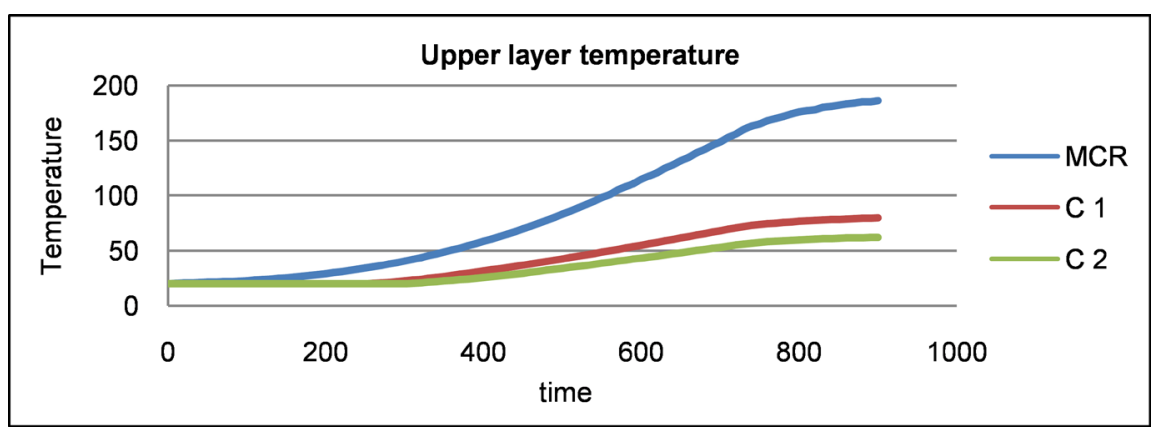

Figure 10. Upper layer temperatures of standard MCR and corridors.

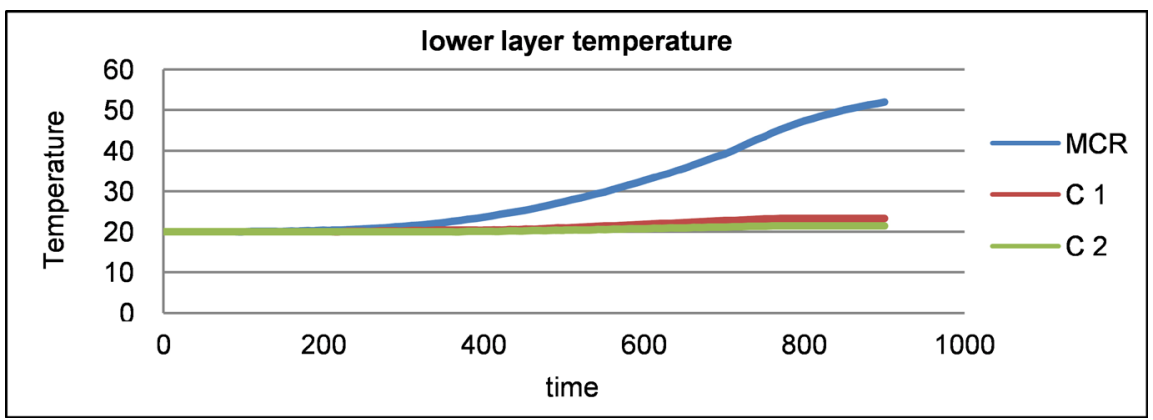

Figure 11. Lower layer temperatures of standard MCR and corridors. 


\subsubsection{Concentration of Fire Produces Gaseous}

Toxic gases produced by combustion are responsible for the fires hazard. The exposure for a certain time to quantities of toxic gases can cause death, thus, it is very important to know the measuring amount of fire toxic gases for safe evacuation. The resulting toxic gases due to the fire are graphically presented with the simulation time. The product gases carbon dioxide $\mathrm{CO}_{2}$, carbon monoxide $\mathrm{CO}$ and hydrogen chloride HCL graphs look similar but they have different values. The resulting gases due to the burning of the cabinet are graphically represented. The product gases are emitted due to burning internal cables and components of the cabinet.

\section{1) Concentration of carbon dioxide $\left(\mathrm{CO}_{2}\right)$}

Carbon dioxide concentration in the upper layer for the standard control room and corridors is shown in Figure 12. Carbon dioxide begins to increase at the control room at $10 \mathrm{sec}$ until it reaches $2.11 \mathrm{E}-2 \mathrm{~mol}$ fraction at $900 \mathrm{sec}$ but delayed until $260 \mathrm{sec}$ to increase in the two corridors reach $0.8 \mathrm{E}-2 \mathrm{~mol}$ fraction in the first corridor and $0.739 \mathrm{E}-2 \mathrm{~mol}$ fraction in the second corridor at $900 \mathrm{sec}$.

Carbon dioxide concentration in the lower layer for the standard MCR and corridors is shown in Figure 13. Carbon dioxide begins to increase in the control room and corridors at the same time $(360 \mathrm{sec})$. In the lower layer, carbon dioxide concentration increases faster in corridors than the control room which has a burning cabinet. From the graph can see that the second corridor is the higher concentration of $2.5 \mathrm{E}-3 \mathrm{~mol}$ fraction While $2.25 \mathrm{E}-3 \mathrm{~mol}$ fraction and $1.67 \mathrm{E}-3 \mathrm{~mol}$ fractions.

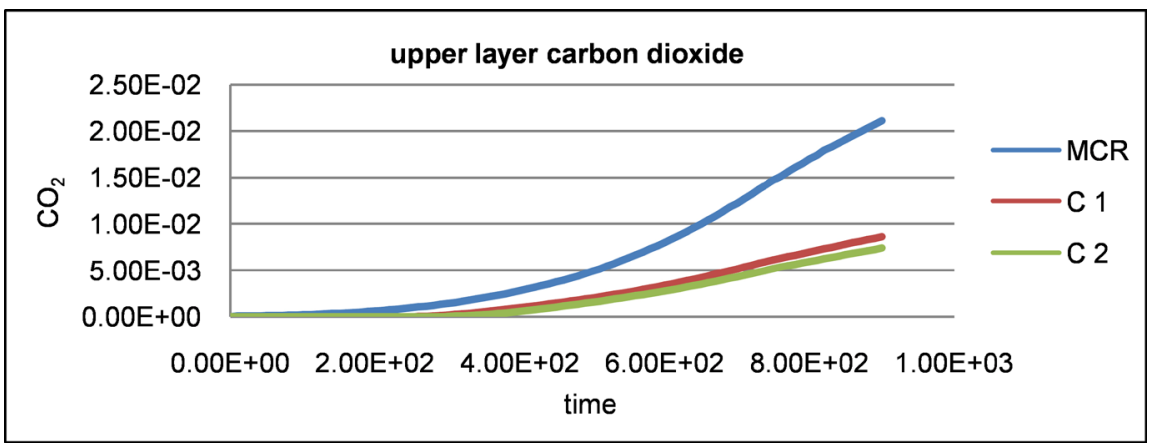

Figure 12. Concentration of carbon dioxide in the upper layer.

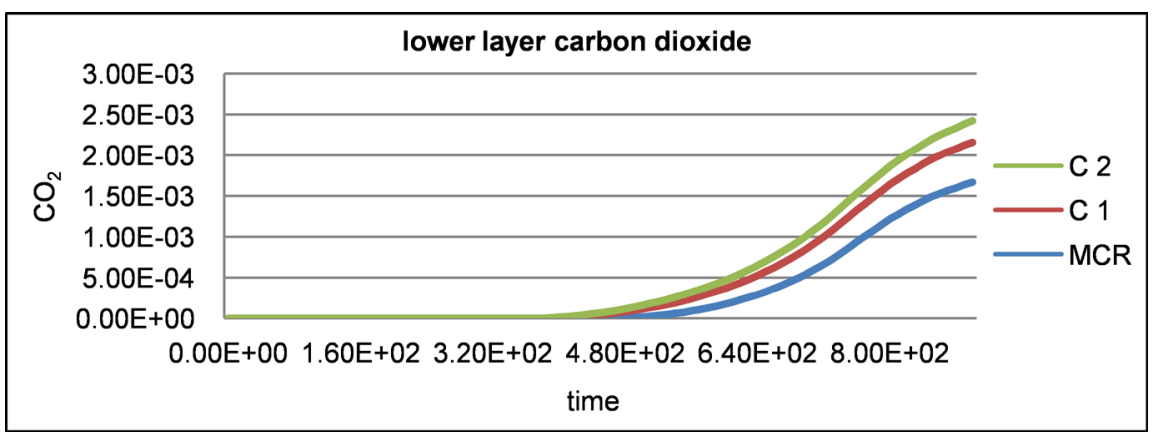

Figure 13. Concentration of carbon dioxide in the lower layer. 


\section{2) Concentration of carbon monoxide (CO)}

Carbon monoxide $(\mathrm{CO})$ in the upper layer for the standard control room and corridors is shown in Figure 14. Carbon monoxide begins to increase at the control room at $1 \mathrm{sec}$ until it reaches $4.65 \mathrm{E}+03 \mathrm{~mol}$ fractions at $900 \mathrm{sec}$ but delayed until $260 \mathrm{sec}$ to increase in the two corridors reach $1.89 \mathrm{E}+03 \mathrm{~mol}$ fraction in the first corridor and $1.62 \mathrm{E}+03 \mathrm{~mol}$ fraction in the second corridor at $900 \mathrm{sec}$.

Carbon monoxide (CO) in the lower layer for the standard control room and corridors is shown in Figure 15. Carbon monoxide begins to increase at the control room and two corridors at the same time $296 \mathrm{sec}$ until reach at $900 \mathrm{sec}$ to $3.56 \mathrm{E}+03 \mathrm{~mol}$ fractions standard MCR, 1.07E+02 mol fraction in the first corridor and $5.70 \mathrm{E}+01 \mathrm{~mol}$ fraction in the second corridor at $900 \mathrm{sec}$.

\section{3) Concentration of hydrogen chloride (HCL)}

Hydrogen Chloride (HCL) causes significant hazards in fires. HCL is causing incapacitation through sensory irritancy which can lead to painful breathing, enlargement of the airways and ultimately death. Hydrogen Chloride (HCL) in part per million (ppm) in the upper layer is shown in Figure 16. Hydrogen Chloride begins to increase at the control room at $1 \mathrm{sec}$ until reach $1.44 \mathrm{E}+04$ ppm at $900 \mathrm{sec}$ but delayed until $260 \mathrm{sec}$ to increase in the first corridor and reached $5.87 \mathrm{E}+03 \mathrm{ppm}$ at 900 and delayed in the second corridor at $300 \mathrm{sec}$ to start increase and reach $5.05 \mathrm{E}+03 \mathrm{ppm}$ at $900 \mathrm{sec}$.

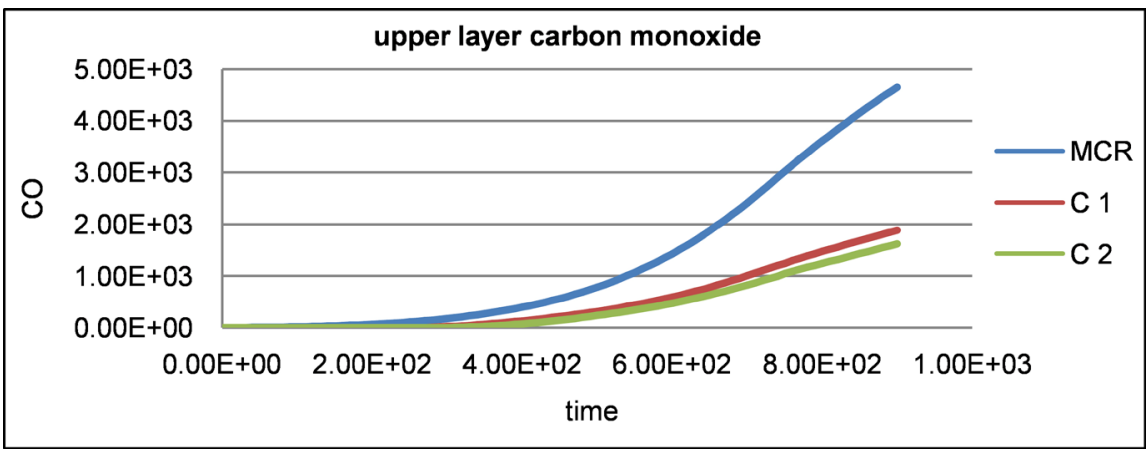

Figure 14. Concentration of carbon monoxide in the upper layer.

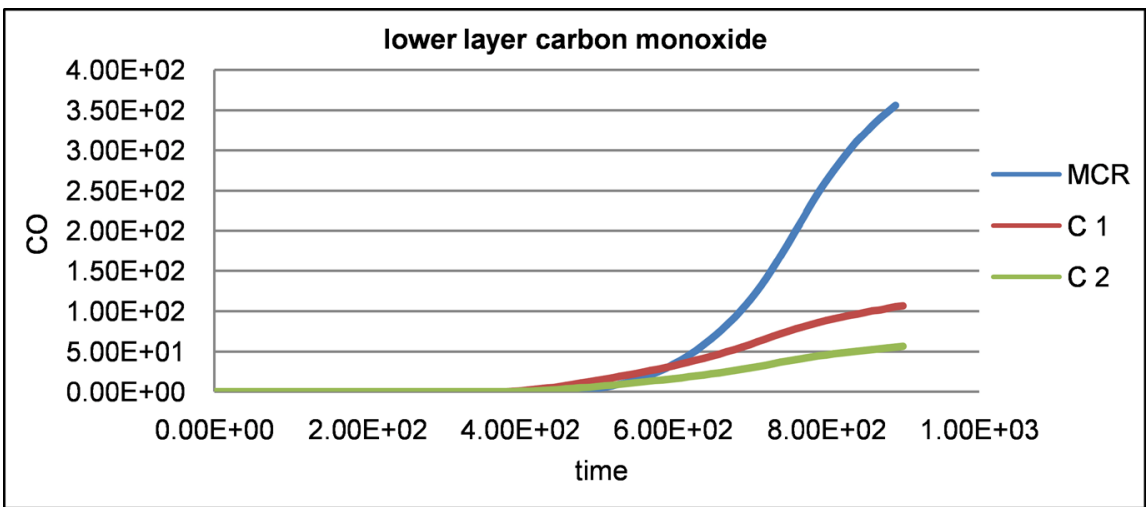

Figure 15. Concentration of carbon monoxide in the lower layer. 
Hydrogen Chloride (HCL) in the lower layer for the standard control room and corridors is shown in Figure 17. Hydrogen Chloride begins to increase at the control room and corridors at the same time $360 \mathrm{sec}$ until reach $900 \mathrm{sec}$ to $1.13 \mathrm{E}+03 \mathrm{ppm}$ in the standard control room, 3.36E+02 ppm in the first corridor and $1.79 \mathrm{E}+02 \mathrm{ppm}$ in the second corridor.

\section{4) Concentration of toxic species fire releases}

Toxic species of fire releases in the upper layer of the standard control room and corridors are shown in Figure 18. Toxic species begins to increase in control room with fire start until reach to $1.87 \mathrm{E}+02 \mathrm{~g} \mathrm{~min} / \mathrm{m}^{3}$ at $900 \mathrm{sec}$ at the end of the simulation but delayed until $260 \mathrm{sec}$ to increase in the first corridor and reached $9.40 \mathrm{E}+01 \mathrm{~g} \mathrm{~min} / \mathrm{m}^{3}$ at $900 \mathrm{sec}$ and delayed in the second corridor at $300 \mathrm{sec}$ to start increase and reach $8.09 \mathrm{E}+01 \mathrm{~g} \mathrm{~min} / \mathrm{m}^{3}$ at $900 \mathrm{sec}$.

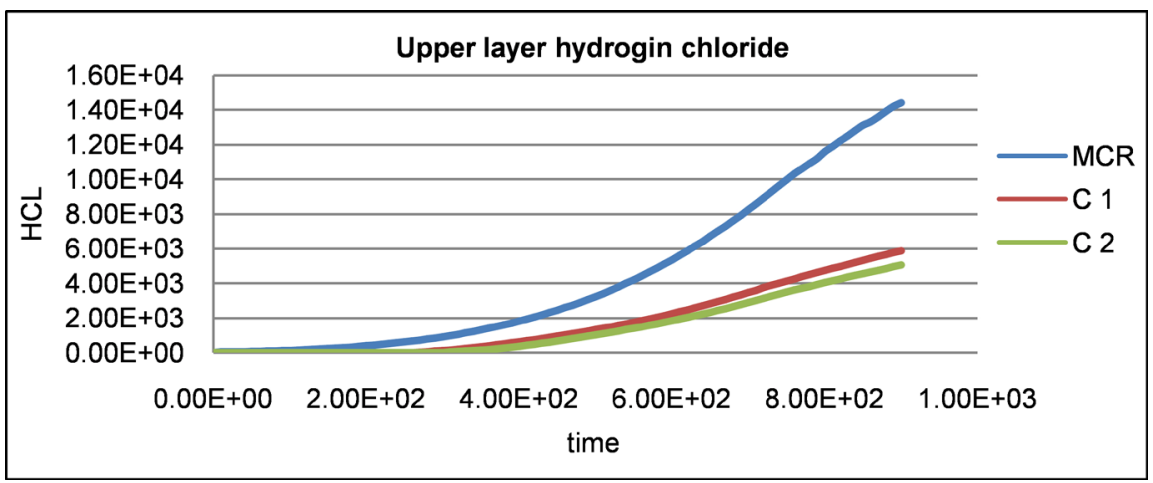

Figure 16. Concentration of HCL in the upper layer.

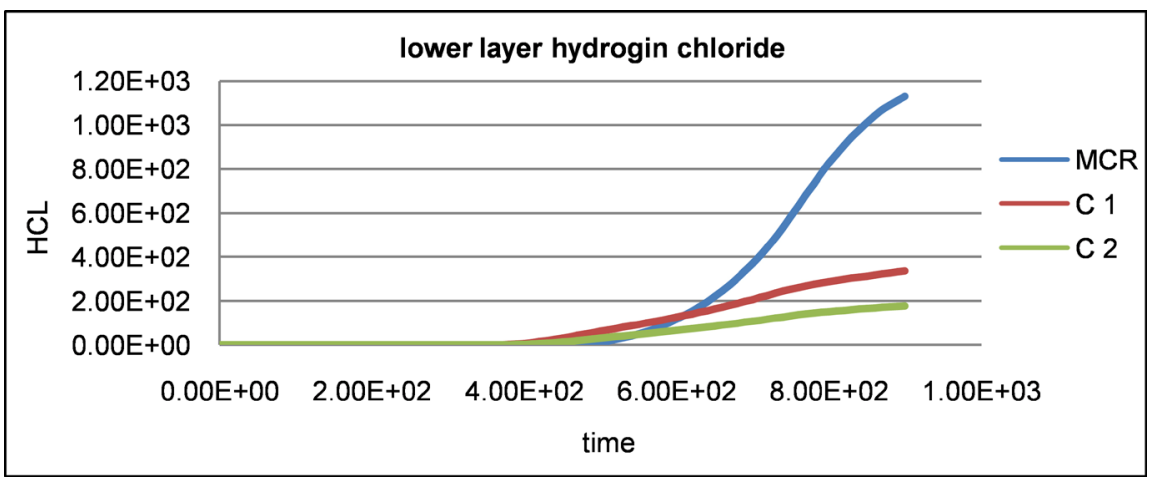

Figure 17. Concentration of HCL in the lower layer.

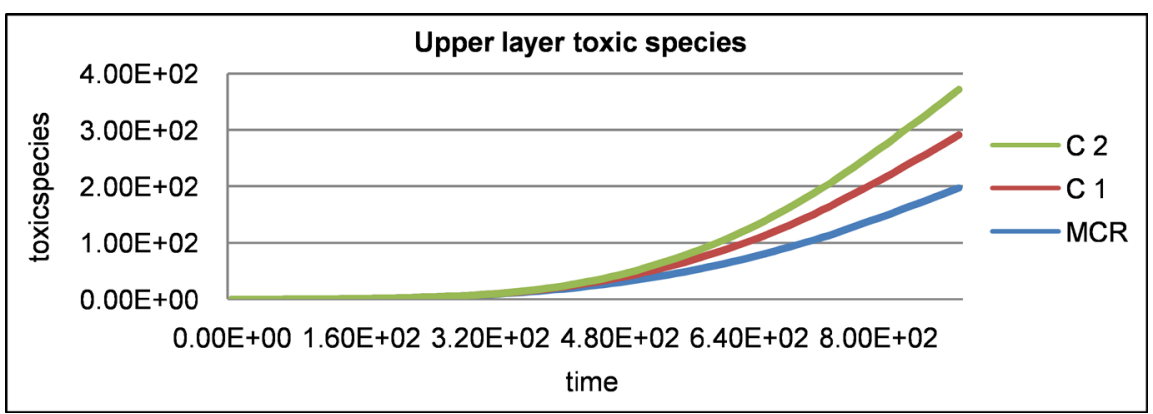

Figure 18. Concentration of toxic species in the upper layer. 
Toxic species of fire releases in the lower layer for the standard control room and corridors are shown in Figure 19. Toxic species begin to increase at the control room and corridors at the same time $360 \mathrm{sec}$ although it increases in corridors higher in beginning put the highest at the end of the simulation. It reaches at $900 \mathrm{sec}$ the end of simulation to $1.75 \mathrm{E}+01 \mathrm{~g} \mathrm{~min} / \mathrm{m}^{3}$ in the standard control room, $6.01 \mathrm{E}+00 \mathrm{~g} \mathrm{~min} / \mathrm{m}^{3}$ in the first corridor and $3.21 \mathrm{E}+00 \mathrm{~g} \mathrm{~min} / \mathrm{m}^{3}$ in the second corridor.

The output result data of CFAST are presented in the Excel sheets [36]. TCP/IP network server side sends the CFAST output Excel sheet to the client-side. Then client-side determines the safest and shortest route as shown in the flowing sections.

\subsection{The Results of the Second Part of PWFEM}

In this part, the Hybrid Safest Shortest Evacuation algorithm (HSSE) is implemented for determining the Shortest and Safest Exit routes according to his evacuees' location. The results of the HSSE divided into three results stages as flowing:

\subsubsection{The Results of the First Stage}

\section{1) The results of the first step (Rule-Based Algorithm)}

In this stage, the safest route is determined for evacuee by using Rule-Based Algorithm, to assist in generating the Safest Route using the CFAST Output Data to remove the danger routes that contain more toxic and hazard gases such as CO \& HCL to use in the next stage of HSSE.

\section{2) The results of the second stage (DV-Hop Algorithm)}

The results from this stage determine the evacuee's node location coordinate in Excel sheet as shown in Figure 20. The Mean square error for each evacuee node must be determined to give the best location determined that give less value. In DV-hop, the output mean square error has low value since, it does not excess about $12 \%$ as shown in Figure 21.

\subsubsection{The Results of the Third Stage}

In this stage, Shortest Route is generated for the safest route that is determined

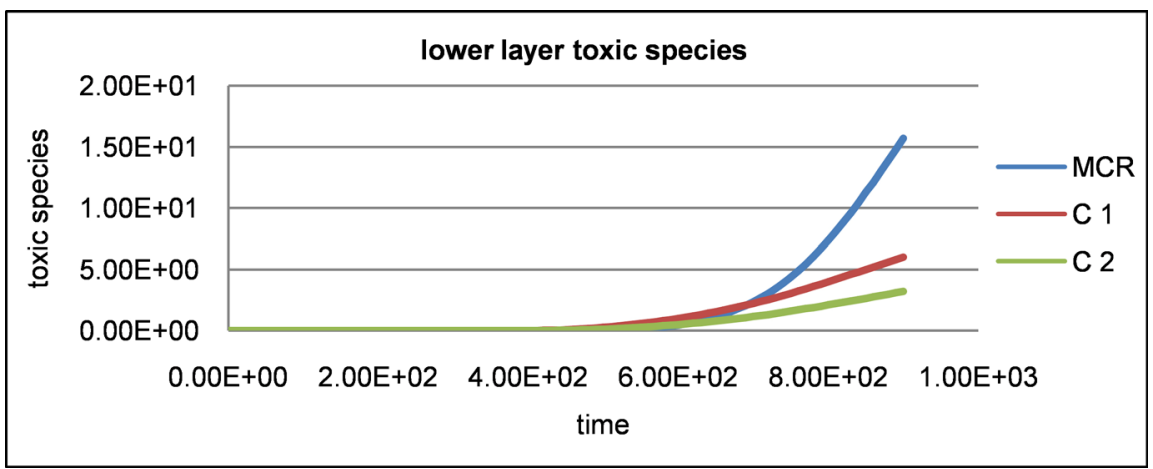

Figure 19. Concentration of toxic species in the lower layer. 


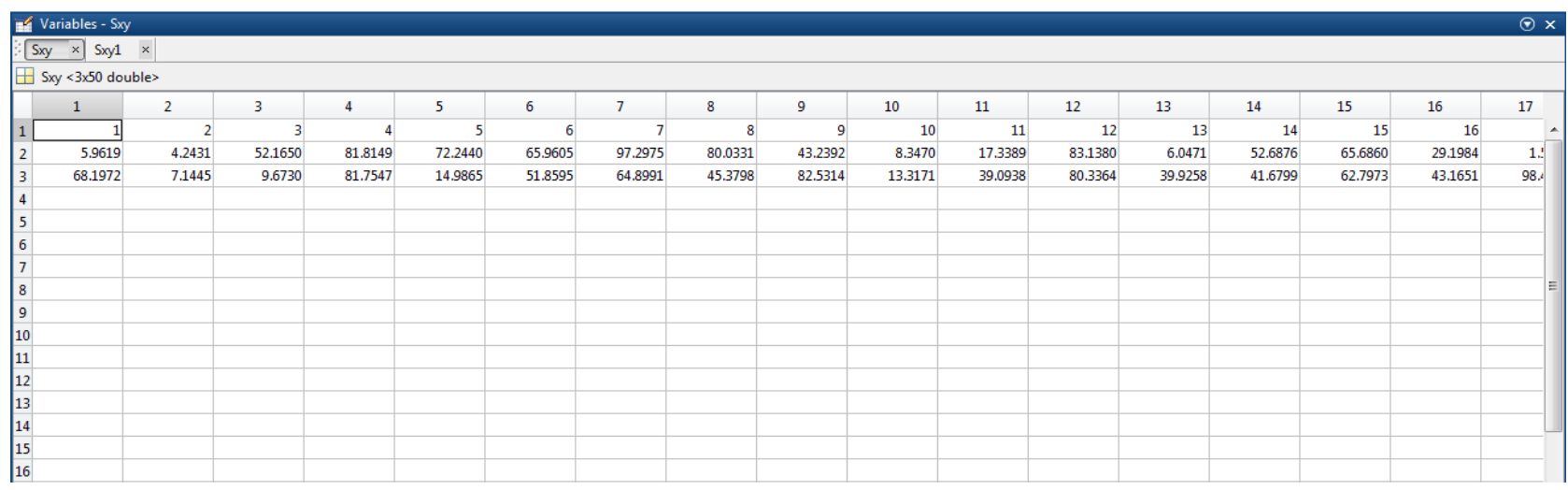

Figure 20. Evacuees node location coordinates.

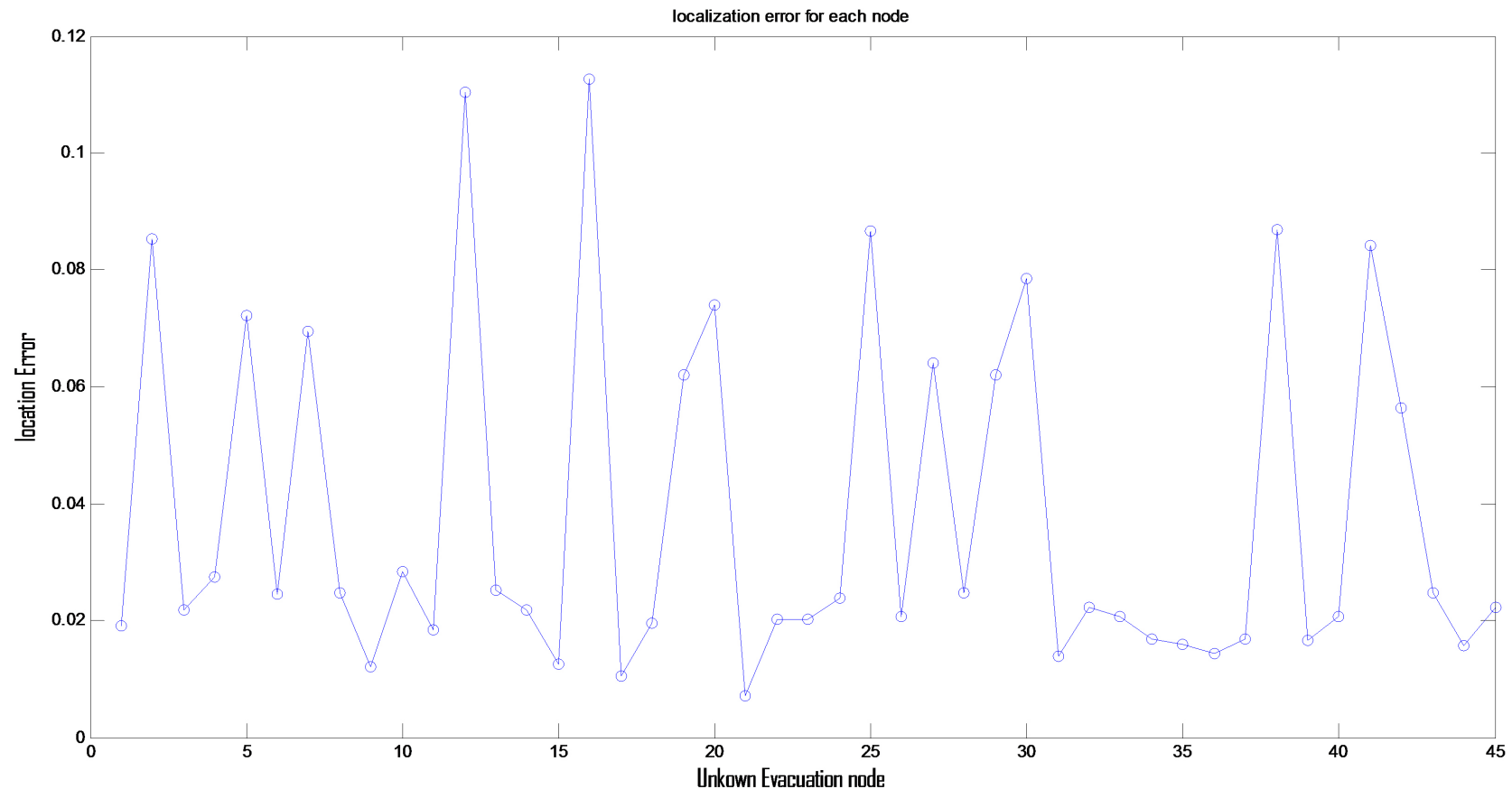

Figure 21. Location average mean square errors for each unknown evacuees node.

in the first stage. The shortest route is generated based on the distance between the evacuee location (source) and Exit (destination) based on the Dijkstra Algorithm. The safest and shortest is displayed in the graph as a tree as shown in Figure 22. The red color of node in the graph obtains the required route. Evacuee's nodes map for Exit, which can be produced in Evacuee's watch is shown in Figure 23.

The results of the second part in PWFEM can be represented in the schematic of NPP layout as shown in Figure 24. The Schematic plant layout used is a two-unit integrated NPP plant [37]. The distance calculation of the shortest route has been carried out between evacuee's location assume at MCR and Exit node. The results of the HSSE in the PWFEM have a unique color to provide the evacuees with the safest shortest evacuation route for Exit from NPP building. The result of the shortest and safest route calculated in the HSSE algorithm embedded in the Dijkstra Algorithm can be generated in numerical form as in Table 2. 


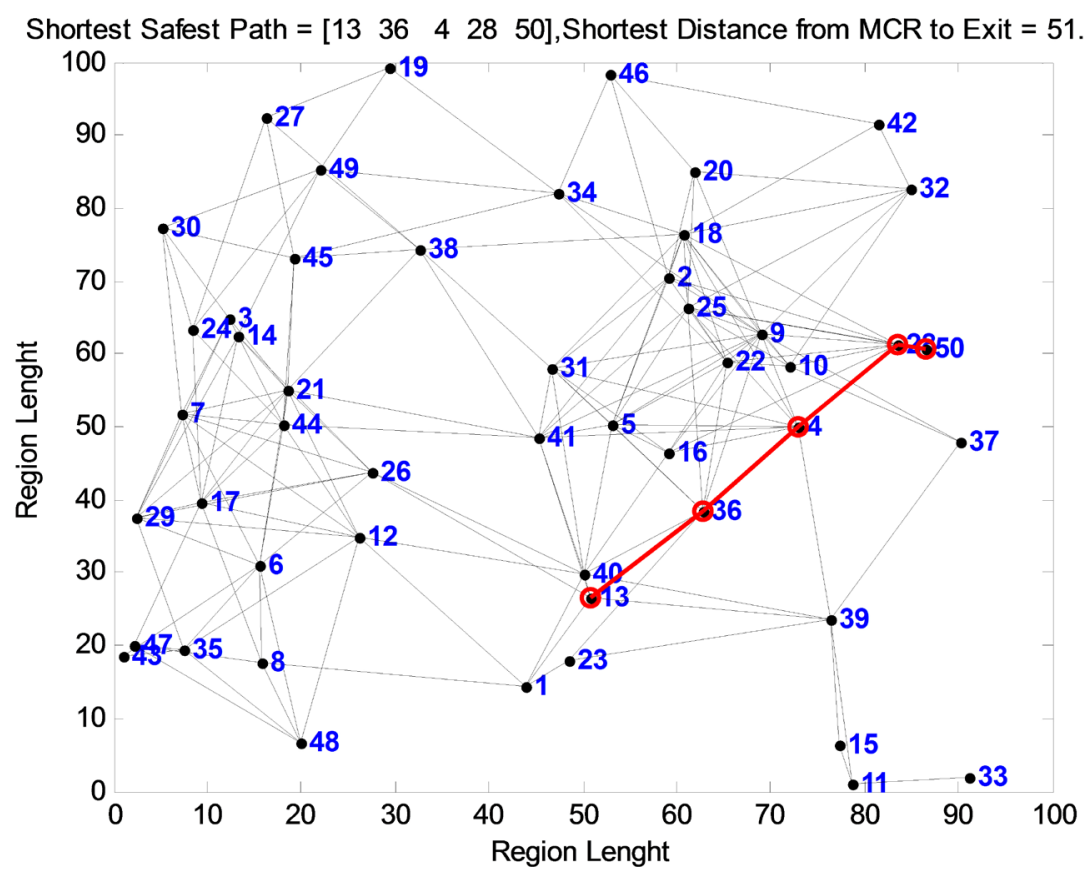

Figure 22. The plan of safest and shortest route.

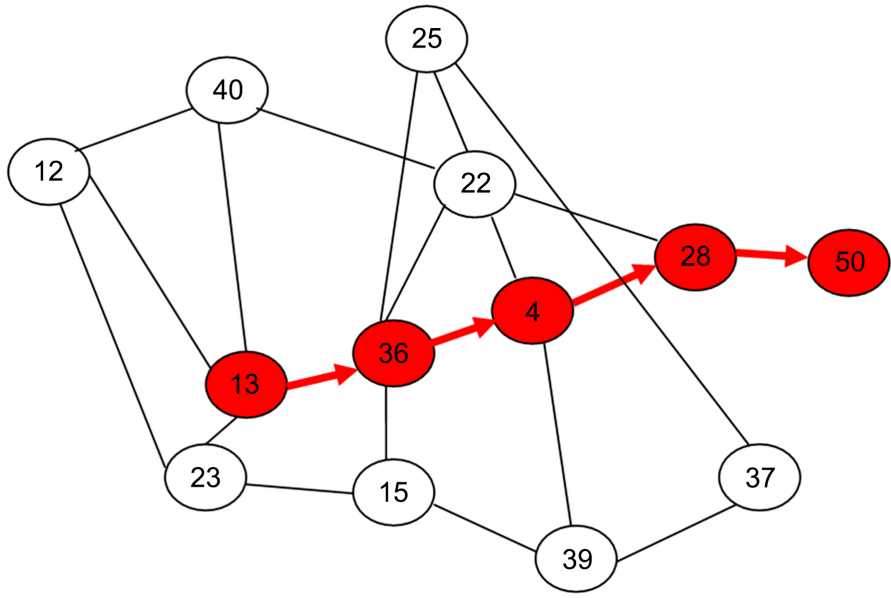

Figure 23. Evacuee's nodes map for exit.

Table 2. Safest shortest safest route.

$\begin{array}{lc}\text { Source ID } & 13 \\ \text { Destination ID } & 50 \\ \text { Distance } & 51.0953\end{array}$




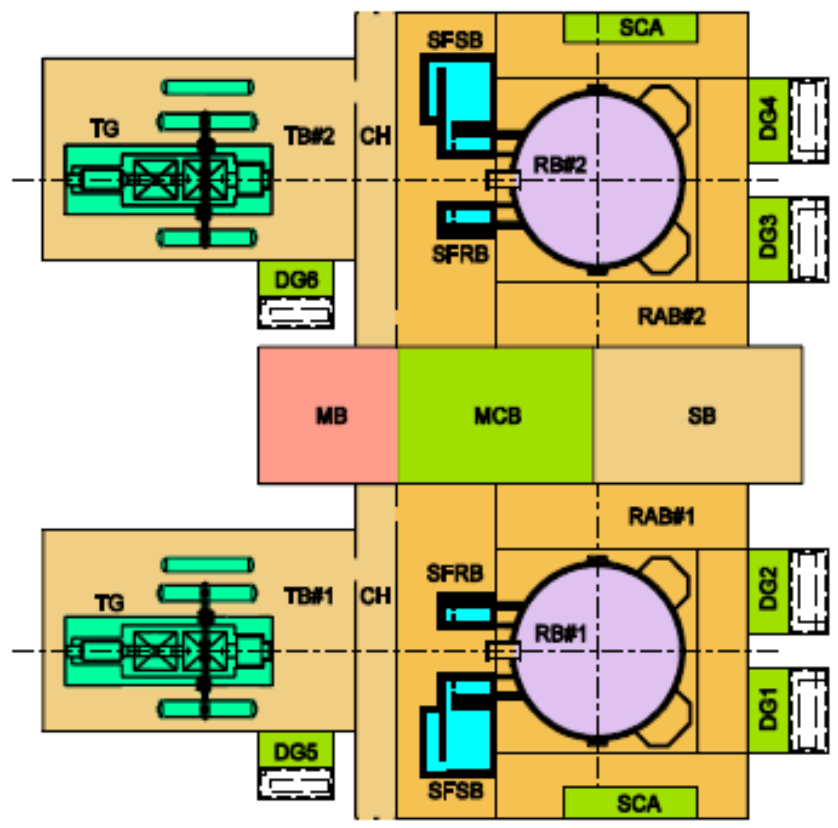

\begin{tabular}{|ll|}
\hline Legend: & \\
CH & Crane hall \\
DG & Diesel generator \\
MCB & Main control building \\
MB & Maintenance building \\
RAB & Reactor auxiliary building \\
RB & Reactor building \\
SB & Service building \\
SCA & Secondary control area \\
SFRB & Spent fuel receiving bay \\
SFSB & Spent fuel storage bay \\
TB & Turbine building \\
TG & Turbine-generator \\
& \\
\hline
\end{tabular}

Figure 24. Evacuee's map in NPP layout.

Evaluation of the Proposed Wireless Fire Evacuation Model realized by calculating the Required Safe Escape Time (RSET) for the proposed wireless fire evacuation model can be determined by:

$$
\mathrm{RSET}=T_{C}+T_{N}+T_{H}
$$

where:

$T_{C}$ : is time takes by the CFAST model to generate fire products data from the ignition, $T_{N}$ : is the time of transfer data through TCP/IP network sides, and $T_{H}$ : is the time of the HSSE algorithm to estimate the safest and shortest route.

The Required Safe Escape Time (RSET) is about one minute. RESET short time so the evacuation process will be improved and shortest. For emergency management, the time for PWFEM is shortest than the predicted time for the evacuation process.

\section{Conclusions}

Fire accidents are very dangerous in NPP since the safety principles must be achieved. Fire evacuation is very important for NPP, so the main goal of this paper is to identify the suitable Safest Shortest exit route in the fire emergency evacuation, by proposing a new Fire Evacuation Model using wireless technique. The Proposed Wireless Fire Evacuation Model (PWFEM) has been developed to imitate emergency fire evacuation cases in NPP.

The Proposed Wireless Fire Evacuation Model (PWFEM) is simulated using a TCP/IP network which consists of two parts server-side and client-side. In the first part, the server-side collects fire products extended in wireless fire sensors at fire ignition in standard MCR which is imitated in the model by the Consolidated Model of Fire Growth and Smoke Transport (CFAST) as a fire zone mod- 
el. In the second part (client-side) Hybrid Safest Shortest Exit HSSE algorithm (which can be loaded in the evacuee's watch) is proposed to determine the safest shortest exit evacuation route for the operator, workers, and visitor in NPP. The HSSE algorithm consists of three stages. The CFAST Output Data is received from the first part used to determine the safest route for the evacuee. The CFAST output data is in an Excel sheet format that represents the concentration of fire gasses emissions as $\mathrm{CO}_{2}, \mathrm{CO}, \mathrm{HCL}$, and toxic species. In the first stage, CFAST output data is used to remove the danger route in the visibility graph to produce the safest route using a rule-based (if-then) algorithm. In the second stage (Evacuees location), the evacuation location is determined based on the Distance Vector Hop (DV-Hop) localization technique. In the third step (Shortest route): the input evacuee's location node (Source ID) and Exit (destination ID) from the second step of HSSE are used to determine the shortest route for evacuee's Exit from NPP building. The total distance will be calculated based on the route from the location of the evacuee to exit. In the final stage, the Safest Shortest Route is generated.

HSSE algorithm plots a visibility graph that represents the Safest Shortest Exit route in evacuee's watches. The escape time taken by Shortest and Safest Evacuation (HSSE) algorithm to estimate the safest and shortest route as a tree, is the smallest time equal to $50.98 \mathrm{sec}$. The PWFEM validated that the independent evacuation preparedness algorithm can be used as emergency fire evacuation model to generate safest and shortest route for evacuee's exit route (HSSE) to guide evacuees to discharge from the NPP building safely. It is more efficient to evacuate evacuees from danger to a safe place especially to evacuees who are unfamiliar with the NPP building, and need to follow the guide and escape safely to overcome the evacuee problem in finding the safest and shortest route. In addition, the Proposed Wireless Fire Evacuation Model (PWFEM) can be used as simulating tool for other places in NPPs or for other high buildings for generating fire evocation plans.

\section{Conflicts of Interest}

The authors declare no conflicts of interest regarding the publication of this paper.

\section{References}

[1] Yu, W. and Li, H. (2012) An Improved DV-Hop Localization Method in Wireless Sensor Networks. 2012 IEEE International Conference on Computer Science and Automation Engineering (CSAE), Zhangjiajie, 25-27 May 2012, 199-202. https://doi.org/10.1109/CSAE.2012.6272938

[2] US Nuclear Regulatory Commission (1990) NUREG 1150-Severe accident risks: an assessment for five US nuclear power plants. Division of Systems Research, Office of Nuclear Regulatory Research, US Nuclear Regulatory Commission, Washington DC.

[3] Zheng, H. and Wei, S. (2018) Technical Insights of SSR-2/1 Safety of Nuclear Power 
Plants: Design (Rev. 1). 2018 26th International Conference on Nuclear Engineering, Paper No: ICONE26-81983, V005T07A013. https://doi.org/10.1115/ICONE26-81983

[4] Aghina, M.A.C., Mól, A.C.A., Jorge, C.A.F., Pereira, C.M., Varela, T.F., Cunha, G.G., et al. (2008) Virtual Control Desks for Nuclear Power Plant Simulation: Improving Operator Training. IEEE Computer Graphics and Applications, 28, 6-9. https://doi.org/10.1109/MCG.2008.86

[5] Stern, W., Berthelot, L. and Bachner, K. (2017) International Scavenging for First Responder Guidance and Tools: IAEA Products. Brookhaven National Laboratory (BNL), Upton, NY. https://doi.org/10.2172/1376089

[6] Li, J.-J. and Zhu, H.-Y. (2018) A Risk-Based Model of Evacuation Route Optimization under Fire. Procedia Engineering, 211, 365-371.

https://doi.org/10.1016/j.proeng.2017.12.024

[7] Choi, M. and Chi, S. (2019) Optimal Route Selection Model for Fire Evacuations Based on Hazard Prediction Data. Simulation Modelling Practice and Theory, 94, 321-333. https://doi.org/10.1016/j.simpat.2019.04.002

[8] Goldberg, A.V. and Harrelson, C. (2005) Computing the Shortest Path: A Search Meets Graph Theory. Proceedings of the 16th Annual ACM-SIAM Symposium on Discrete Algorithms, Society for Industrial and Applied Mathematics 3600 University City Science Center Philadelphia, PA, United States, January 2005, 156-165. https://doi/10.5555/1070432.1070455

[9] Xing, Z. and Tang, Y. (2012) Simulation of Fire and Evacuation in High-Rise Building. Procedia Engineering, 45, 705-709.

https://doi.org/10.1016/j.proeng.2012.08.227

[10] Chen, Y.-Z., Shen, S.-F., Chen, T. and Yang, R. (2014) Path Optimization Study for Vehicles Evacuation Based on Dijkstra Algorithm. Procedia Engineering, 71, 159-165. https://doi.org/10.1016/j.proeng.2014.04.023

[11] Liu, D., Gu, T. and Xue, J.-P. (2010) Rule Engine Based on Improvement Rete Algorithm. The 2010 International Conference on Apperceiving Computing and Intelligence Analysis Proceeding, Chengdu, 17-19 December 2010, 346-349. https://doi.org/10.1109/ICACIA.2010.5709916

[12] Zhang, Q., Zhang, W., Li, Y., Wang, J., Zhang, L. and Hou, T. (2012) A Rule-Based Algorithm for Automatic Bond Type Perception. Journal of Cheminformatics, 4, Article No. 26. https://doi.org/10.1186/1758-2946-4-26

[13] Chen, K., Wang, Z.-H., Lin, M. and Yu, M. (2010) An Improved DV-Hop Localization Algorithm for Wireless Sensor Networks. IET International Conference on Wireless Sensor Network 2010 (IET-WSN2010). https://doi.org/10.1049/cp.2010.1063

[14] Golden, B. (1976) Technical Note-Shortest-Path Algorithms: A Comparison. Operations Research, 24, 1164-1168. https://doi.org/10.1287/opre.24.6.1164

[15] Walton, W.D., Carpenter, D.J. and Wood, C.B. (2016) Zone Computer Fire Models for Enclosures. In: Hurley, M.J., et al., Eds., SFPE Handbook of Fire Protection Engineering. Springer, New York, 1024-1033. https://doi.org/10.1007/978-1-4939-2565-0 31

[16] Rein, G., Bar-Ilan, A., Fernandez-Pello, A.C. and Alvares, N. (2006) A Comparison of Three Models for the Simulation of Accidental Fires. Journal of Fire Protection Engineering, 16, 183-209. https://doi.org/10.1177/1042391506056926

[17] Fonollosa, J., Solórzano, A. and Marco, S. (2018) Chemical Sensor Systems and Associated Algorithms for Fire Detection: A Review. Sensors, 18, 553. 
https://doi.org/10.3390/s18020553

[18] UNRC Division of Human Factors Safety (1981) Guidelines for Control Room Design Reviews, Vol. 88. Division of Human Factors Safety, Office of Nuclear Reactor Regulation.

[19] UNRC (2007) Verification and Validation of Selected Fire Models for Nuclear Power Plant Applications. NUREG-1824 (EPRI 1011999), Washington DC.

[20] Babrauskas, V. (2003) Ignition Handbook Vol. 318. Fire Science Publishers, Issaquah.

[21] Purser, D.A., Rowley, J.A., Fardell, P.J. and Bensilum, M. (1999) Fully Enclosed Design Fires for Hazard Assessment in Relation to Yields of Carbon Monoxide and Hydrogen Cyanide. Proceedings of Interflam'99, Interscience Communications, London, 1163-1169.

[22] UNRC (2012) Nuclear Power Plant Fire Modeling Analysis Guidelines (NPP FIRE MAG). NUREG-1934, Washington DC.

[23] Afshar, C., Najafi, B., Joglar, F., Li, Y., Henneke, D., Warner, M., et al. (2010) Fire Probabilistic Risk Assessment Methods Enhancements (NUREG/CR-6850 and EPRI 1011989, Supplement 1). EPRI and NRC.

[24] Ojugo, A., Eboka, A., Okonta, O., Yoro, R. and Aghware, F. (2012) Genetic Algorithm Rule-Based Intrusion Detection System (GAIDS). Journal of Emerging Trends in Computing and Information Sciences, 3, 1182-1194.

[25] Ray, S., Starobinski, D., Trachtenberg, A. and Ungrangsi, R. (2004) Robust Location Detection with Sensor Networks. IEEE Journal on Selected Areas in Communications, 22, 1016-1025. https://doi.org/10.1109/JSAC.2004.830895

[26] Xu, T. and Cai, Y. (2008) Exploring Historical Location Data for Anonymity Preservation in Location-Based Services. IEEE INFOCOM 2008-The 27th Conference on Computer Communications, Phoenix, 13-18 April 2008, 547-555. https://doi.org/10.1109/INFOCOM.2007.103

[27] Li, X., Mao, Y. and Liang, Y. (2008) A Survey on Topology Control in Wireless Sensor Networks. 2008 10th International Conference on Control, Automation, Robotics and Vision, Hanoi, Vietnam, 17-20 December 2008, 251-255.

[28] Kuo, S.-P., Wu, B.-J., Peng, W.-C. and Tseng, Y.-C. (2007) Cluster-Enhanced Techniques for Pattern-Matching Localization Systems. 2007 IEEE International Conference on Mobile Adhoc and Sensor Systems, Pisa, 8-11 October 2007, 1-9. https://doi.org/10.1109/MOBHOC.2007.4428664

[29] Stojanović, D. and Stojanović, N. (2014) Indoor Localization and Tracking: Methods, Technologies and Research Challenges. Facta Universitatis, Series: Automatic Control and Robotics, 13, 57-72.

[30] Barnes, M., Leather, H. and Arvind, D. (2007) Emergency Evacuation Using Wireless Sensor Networks. 32nd IEEE Conference on Local Computer Networks (LCN 2007), Dublin, 15-18 October 2007, 851-857. https://doi.org/10.1109/LCN.2007.48

[31] Kumar, S. and Lobiyal, D. (2013) An Advanced DV-Hop Localization Algorithm for Wireless Sensor Networks. Wireless Personal Communications, 71, 1365-1385. https://doi.org/10.1007/s11277-012-0880-3

[32] Kaur, A., Gupta, G.P. and Kumar, P. (2017) A Survey of Recent Developments in DV-Hop Localization Techniques for Wireless Sensor Network. Journal of Telecommunication, Electronic and Computer Engineering (JTEC), 9, 61-71.

[33] Huang, Y. (2018) Research on the Improvement of Dijkstra Algorithm in the Shortest Path Calculation. In: Proceedings of the 2017 4th International Conference 
on Machinery, Materials and Computer (MACMC2017), Atlantis Press, 745-749. https://doi.org/10.2991/macmc-17.2018.141

[34] Dijkstra, E.W. (1959) A Note on Two Problems in Connexion with Graphs. Numerische Mathematik, 1, 269-271. https://doi.org/10.1007/BF01386390

[35] Hurley, M.J., Gottuk, D.T., Hall Jr., J.R., Harada, K., Kuligowski, E.D., Puchovsky, M., et al. (2015) SFPE Handbook of Fire Protection Engineering. Springer. https://doi.org/10.1007/978-1-4939-2565-0

[36] Peacock, R.D., Reneke, P.A. and Forney, G.P. (2017) CFAST-Consolidated Model of Fire Growth and Smoke Transport (Version 7) Volume 2: User's Guide. NIST Technical Note 1889v2.

[37] Bonechi, M. (2006) Advanced CANDU Reactor (ACR) Safety Design Approach. Advanced Nuclear Plant Design Options to Cope with External Events, p. 163. 